


\title{
ASPECTOS GERAIS DA ÁREA CÁRSTICA DE AURORA DO TOCANTINS (BRASIL)
}

\author{
GENERAL ASPECTS OF KARST AREA OF \\ AURORA DO TOCANTINS (BRAZIL)
}

F. Morais ${ }^{1}$

Resumo - Além de toda importância sóciocultural, o relevo cárstico, ou sistema cárstico, constitui importante ferramenta para se entender a fisiologia da paisagem atual, além de fornecer indícios acerca da paleogeografia e paleoclimatologia. No estado do Tocantins existem apenas poucos trabalhos, de natureza descritiva, acerca do relevo cárstico, tendo sua maioria sido desenvolvida na regiáo do extremo sudeste do estado, com destaque para as cidades de Dianópolis e Aurora do Tocantins, que apresentam grande potencial para a ocorrência de cavernas. O presente estudo busca fazer uma descrição dos aspectos geomorfológicos da área cárstica de Aurora do Tocantins; além de tecer alguns comentários acerca do uso e ocupação no entorno das cavernas dessa área no norte do Brasil. Foram realizados trabalhos de campo na área cárstica denominada Aurora do Tocantins, pelo fato de ter como base de apoio a cidade homônima. Durante esses trabalhos foi feita uma caracterizaçáo geral do exocarste e do endocarste, com anotaçóes das principais feiçóes espeleológicas e uso da terra. Foram ainda feitas consideraçóes sobre o estado de conservação das cavernas da área estudada. De maneira geral, os resultados apontaram que a maioria das cavidades se desenvolve sobre rochas calcárias do Grupo Bambuí e estão em áreas dominadas por agricultura e pastagens. A presença de água no interior das cavidades dá indícios de que as mesmas encontram-se em franco processo de desenvolvimento. No tocante às intervençôes antrópicas, pode-se notar que algumas feiçôes como dolinas e fendas calcárias têm sido utilizadas para a disposição irregular de lixo.

Palavras-chave - Geomofologia cárstica; Cavernas; Tocantins; Brasil

Abstract-In addition to all its socio cultural importance, the karst relief, or karst system, is an important tool for understanding the present landscape physiology, and provides clues about paleogeography and paleoclimatology. In the Tocantins state descriptive studies about the karst

1 Rua 03, Q. 17, s/n, Jardim dos Ipês, Porto Nacional - TO - Brasil; morais@uft.edu.br 
relief are scarce, having most of them been developed in the region of extreme southeast of the state, especially in the Dianópolis and Aurora do Tocantins cities, which have great potential for the occurrence of caves. This study seeks to provide a description of the geomorphological aspects of the karst area of Aurora do Tocantins, and to present several comments about the land use in the vicinity of the caves of this area in northern Brazil. Fieldwork has been carried out in the karstic area named Aurora do Tocantins, using as support the homonymous city. During this work, a general characterization of the exokarst and endokarst has been done, and the major speleological features and land use have been pointed out. The state of conservation of caves in the studied area was also considered. Overall, the results indicated that most cavities grows on limestone rocks of the Bambui Group and are located in areas dominated by agriculture and pasture. The presence of water inside the cavities provides evidence that their development process are in progress. With regard to human interventions, it may be noted that some features as dolines and cracks has been used for the illegal waste disposal.

Keywords - Karst geomorphology; Caves; Tocantins state; Brazil

\section{1 - Introduçáo}

Desde a antiguidade, as cavernas e seu entorno têm sido utilizados para diversos fins. Locais de realização de cultos religiosos, sepultamentos e abrigo contra intempéries são algumas das mais antigas utilizaçôes destes ambientes pelos seres humanos. Uma das características do ambiente espeleológico refere-se às pinturas rupestres, que representam uma tentativa do homem registrar as características fisiográficas do espaço habitado, além da organização sócioespacial de seu cotidiano (LINO, 2001).

Dentre os vários estudos pioneiros feitos no Brasil, destacam-se aqueles realizados por naturalistas estrangeiros, como Peter Wilhelm Lund (séc. xix) e Richard Krone (séc. xx), nos estados de Minas Gerais e São Paulo, respectivamente.

KARMANN \& SÁNCHEZ (1979) apresentaram uma distribuição das províncias espeleológicas no Brasil, apontando a região do extremo sudeste do estado do Tocantins, com destaque para Dianópolis e Aurora do Tocantins, como sendo uma área com grande potencial para a ocorrência de cavernas.

Os trabalhos na regiáo inicialmente visavam apenas a exploração, mapeamento e catalogaçáo de cavernas. Contudo, mais recentemente, estas pesquisas começaram a tomar caráter mais científico, com a participação de professores e alunos de graduação e pós-graduação de várias universidades brasileiras, contabilizando mais de uma centena de cavernas descobertas e cadastradas até janeiro de 2012.

O presente estudo busca fazer uma descrição dos aspectos físicos da área cárstica de Aurora do Tocantins, além de tecer alguns comentários acerca do uso e ocupação no entorno das cavernas dessa área no norte do Brasil.

\section{2 - Área de estudo}

A área cárstica de Aurora do Tocantins está situada na porção sudeste do estado do Tocantins, na região norte do Brasil. Os levantamentos realizados neste trabalho estão compreendidos em uma área de $6099,58 \mathrm{~km}^{2}$, entre os paralelos $12^{\circ} 10^{\prime} 00^{\prime \prime} \mathrm{S}$ e $13^{\circ} 05^{\prime} 00^{\prime \prime} \mathrm{S}$ e 


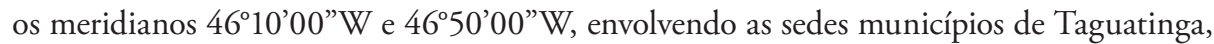
Aurora do Tocantins, Lavandeiras, Combinado e Novo Alegre, além de cobrir uma parte do município de Campos Belos, no estado de Goiás.

De acordo com a SEPLAN (2008), o clima da região é considerado Sub-úmido Seco com moderada deficiência hídrica no inverno. Apresenta precipitaçóes médias anuais entre 1400 e $1600 \mathrm{~mm}$ e temperatura média anual variando entre 25 e $27^{\circ} \mathrm{C}$.

No que diz respeito à geologia, a área de estudo situa-se nos domínios da Bacia Sedimentar Sanfranciscana, com ocorrência das seguintes unidades geológicas da base para o topo: Complexo Almas-Cavalcante (Embasamento Cristalino), Grupo Bambuí, Grupo Urucuia, Grupo Areado e Depósitos Aluvionares Recentes.

Segundo CAMPOS \& DARDENE (1997), o Grupo Urucuia data do Cretáceo e é composto pelas formaçóes Posse e Araras, sendo constituído por arenitos, com níveis de pelitos, arenitos conglomeráticos e ocorrências de conglomerados. $\mathrm{Na}$ área cárstica de Aurora do Tocantins, este grupo é mais visível na porção leste, nos afloramentos que compóem a Serra Geral, mas também pode ser notado em vários outros pontos região.

De acordo com SOUZA et al. (2004), o Grupo Bambuí, de idade neoproterozóica, é composto por calcarenitos, dolomitos, ritimitos, margas, argilitos, siltitos, arcoses e calcários, que compóem o Subgrupo Paraopeba, que se distribui por grande parte da área de estudo e comporta a maioria das feiçóes cársticas.

A geomofologia da área é dominada por um pediplano degradado inumado, que constitui a Serra Geral. Esta serra constitui o Planalto Divisor das Bacias Hidrográficas dos rios São Francisco e Tocantins (Fig. 1). Segundo BRASIL (1982), esse tipo de modelado constitui-se de formas aplanadas parcialmente conservadas, tendo sido remoldadas em função das mudanças no sistema morfogenético. Escarpas separam este modelado das formas de dissolução, constituindo uma superfície de aplanamento retocada inumada, que passou por vários eventos de retomada dos processos erosivos, dando-lhes uma morfologia dominada por planos inclinados e levemente côncavos em alguns lugares. Tais fases de retomada erosiva são denunciadas pela presença de cobertura detrítica e encouraçamentos, que podem ser vistos, principalmente, na porção centro-leste da área de estudo.

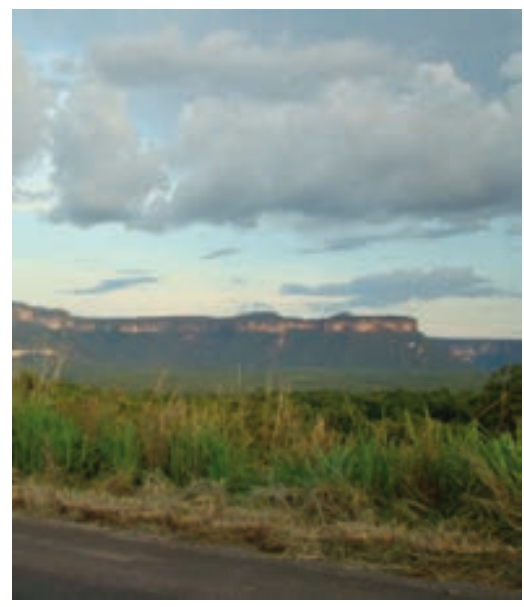

Fig. 1 - Escarpas da Serra Geral, porção leste da área de estudo. 
Os modelados de dissolução, presentes na área, podem ser divididos em três classes, carste coberto, carste em exumação e carste descoberto. As formas cobertas e em processo de exumação ocorrem principalmente na porção centro-leste da área, tornando-se menos visíveis à medida que se aproximam da Serra Geral. Já o carste descoberto, que é caracterizado por formas como lapiás, dolinas, uvalas, poljés e cavernas, dentre outras feiçóes, é mais visível na porção central, com grandes afloramentos distribuídos no sentido sul-norte, além de ocorrem também na porção sudoeste da área de estudo. Ocorrem ainda, de maneira pontual, planícies de acumulaçóes recentes. Segundo BRASIL (1982), essas áreas correspondem aos pontos de acumulação fluvial, caracterizados como várzeas, que são propícias a inundações periódicas em função dos regimes fluviais das drenagens da bacia hidrográfica a que pertencem.

\section{3 - Exocarste}

O exocarste pode ser entendido como o conjunto de formas que caracterizam ou individualizam o relevo cárstico quando comparado às formas de relevo circunvizinhas. Mesmo sabendo da possibilidade de classificação do sistema cárstico em sua totalidade, buscou-se aqui apontar apenas as formas superficiais mais típicas desse tipo de relevo, como os lapiás (karren), as dolinas, os poljes e os maciços calcários.

Os lapiás ou karren, como têm sido ultimamente chamados no Brasil, são feiçôes de dissolução quase sempre de pequenas dimensóes, que podem se desenvolver no exocarste, epicarste e endocarste (FORD \& WILLIAMS, 2007). Uma classificação detalhada dessas feiçóes foi elaborada por BÖGLI (1980), que definiu três grandes grupos de lapiás baseado em suas características genéticas (free karren, half free e covered karren). FORD \& WILLIAMS (2007) apresentam uma classificação dos lapiás baseada em sua forma (formas circulares em planta, formas lineares controladas por fraturas, formas lineares hidrodinamicamente controladas e formas poligenéticas).

$\mathrm{Na}$ área cárstica de Aurora do Tocantins ocorrem lapiás das mais diversas naturezas, com destaque para os lapiás verticais (rillenkarren) e os lapiás horizontais (Schichtenkarren), além de lapiás em pináculos (Spitzenkarren), em menor quantidade.

Dolinas são apontadas por FORD \& WILLIAMS (2007) como depressóes cársticas de dimensões pequenas a intermediárias, podendo ter sua gênese ligada a fatores tanto climáticos quanto estruturais. Durante os trabalhos de campo, foi possível notar que as dolinas se distribuem por toda a área estudada, sendo mais notáveis na porção central, nas proximidades da cidade de Aurora do Tocantins. No extremo noroeste da área, ocorrem diversas lagoas conectadas a canais de primeira ordem dos tributários do rio Ponte Alta (Fig. 2). Pelo formato das lagoas e pela coloração de suas águas, pode-se inferir que as mesmas são de origem cárstica (dolinas alargadas). Contudo, para a confirmação dessa hipótese se faz necessário a confirmação de campo, além de estudo geológico mais detalhado acerca da batimetria e estratigrafia de fundo dessas lagoas.

Os poljes podem ser entendidos como grandes depressóes de base plana com planícies de dissolução em seu interior (FORD \& WILLIAMS, 2007). PALMER (2007, p. 412) ressalta que tais planícies de dissolução geralmente constituem o nível de base local e podem ser comparadas às planícies de inundaçóes dos vales fluviais maduros. 


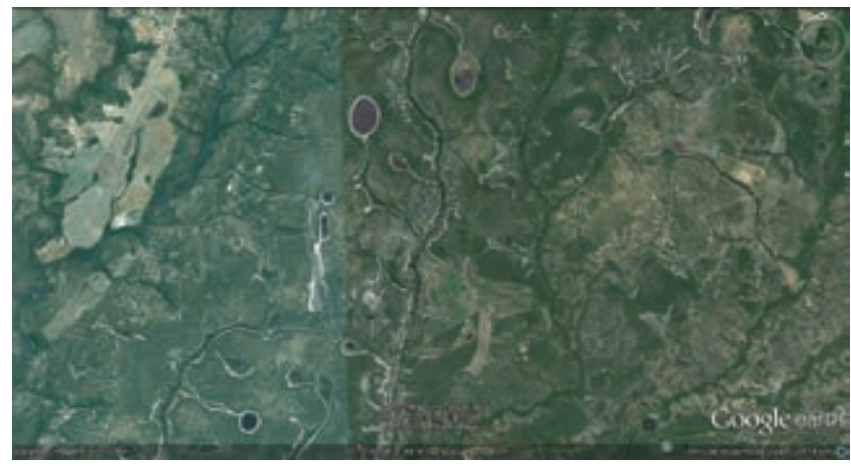

Fig. 2 - Lagoas (cársticas?) situadas na porção noroeste da área de estudo

(Fonte: GoogleEarth, 2004).

$\mathrm{Na}$ área estudada, três poljes chamam a atenção, um onde se situa o núcleo urbano de Aurora do Tocantins (Fig. 3), outro situado a aproximadamente $7 \mathrm{~km}$ da cidade de Combinado (lado esquerdo da pista, no sentido Combinado - Aurora do Tocantins) e um terceiro grande polje, com mais de $5 \mathrm{~km}$ em sua maior extenção interior, na porção centro-leste da área (coordenadas geográficas S $12^{\circ} 45^{\prime} 35^{\prime}$ e W $46^{\circ} 43^{\prime} 19^{\prime}$ ), entre o córrego Tiúba e a Serra do Canabraval.

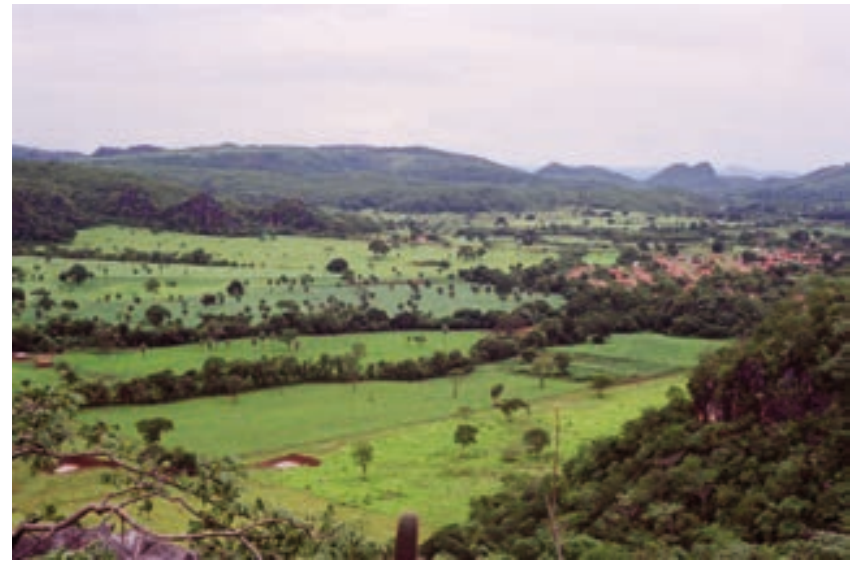

Fig. 3 - Polje envolvendo a área urbana de Aurora do Tocantins

(Foto: Acervo da SBE).

\section{4 - Uso e ocupação do solo}

Com intuito de compreender como se dá o uso e ocupação da terra na área cárstica de Aurora do Tocantins, foi elaborado um mapa temático que aponta as principais formas de aproveitamento do solo na região. Para tanto, foram utilizadas imagens do satélite 
Landsat 5 sensor TM (Thematic Mapper), com resolução espacial de 30 metros, referentes ao mês de abril do ano de 2010.

Após as correçôes geométricas, utilizando como base de tela as imagens ortorretificadas disponibilizadas pela Secretaria de Planejamento do Estado do Tocantins, foram inseridas em um banco de dados geográficos através do software gratuito SPRING 5.1.7.

Com uso da composição colorida das bandas 5(R) 4(G) 3(B), foi feita a segmentaçáo da imagem em cinco classes temáticas: agricultura/pastagens, vegetação natural, afloramentos rochosos, solo exposto e área urbana.

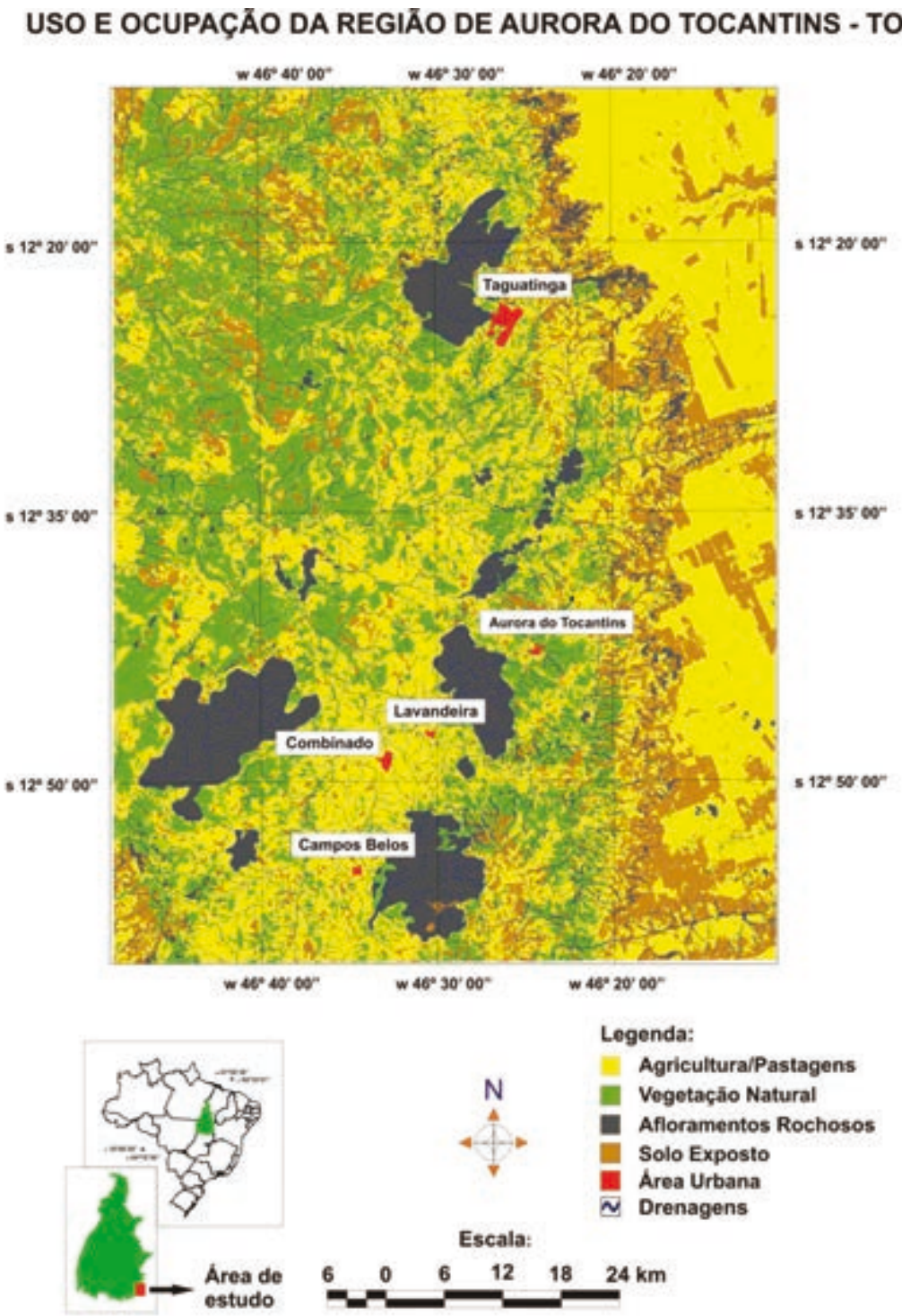

Fig. 4 - Mapa de uso e ocupação do solo na área cárstica de Aurora do Tocantins. 
O mapa de uso e ocupação mostra que os maiores afloramentos calcários estão situados na porção central da área, distribuídos no sentido sul-norte, além de uma grande ocorrência na porção sudoeste (Fig. 4). No mesmo mapa é possível notar que grande parte da área é destinada ao uso agrícola, com destaque para a porção oeste, onde as plantaçóes de soja nos platôs da Serra Geral dominam a paisagem. O desmatamento nesta área tem preocupado a populaçáo local, tendo em vista que ali se localiza grande parte das nascentes dos cursos fluviais que abastecem a regiāo.

\section{5 - Endocarste}

As dez maiores cavernas estudadas na região estão situadas na porção central da área (Tabela 1). Isso se deve ao fato de quase todas as expediçóes terem como base de apoio a cidade de Aurora do Tocantins.

Tabela 1 - Lista das dez maiores cavernas da área de estudo segundo os dados da Sociedade Brasileira de Espeleologia.

\begin{tabular}{|c|c|c|c|c|}
\hline Nome & $\begin{array}{l}\text { Coordenadas } \\
\text { Geográficas }\end{array}$ & Litologia & $\begin{array}{c}\text { Altura do } \\
\text { afloramento rochoso }\end{array}$ & $\begin{array}{c}\text { Desenvolvimento } \\
\text { Linear }\end{array}$ \\
\hline Gruta dos Moura & $\begin{array}{c}\mathrm{S} 12^{\circ} 34^{\prime} 537^{\prime \prime} \mathrm{W} \\
46^{\circ} 30^{\prime} 586^{\prime \prime}\end{array}$ & Calcário & $-60 \mathrm{~m}$ & $1.000 \mathrm{~m}$ \\
\hline $\begin{array}{l}\text { Caverna D. } \\
\text { Conceição }\end{array}$ & $\begin{array}{c}\mathrm{S} 12^{\circ} 36^{\prime} 602^{\prime \prime} \mathrm{W} \\
46^{\circ} 24303^{\prime \prime}\end{array}$ & Calcário & $-40 \mathrm{~m}$ & --.---- \\
\hline Gruta do Culto & $\begin{array}{c}S 12^{\circ} 37^{\prime} 070^{\prime \prime} \mathrm{W} \\
46^{\circ} 26^{\prime} 006^{\prime \prime}\end{array}$ & Calcário & $-70 \mathrm{~m}$ & $649,20 \mathrm{~m}$ \\
\hline $\begin{array}{l}\text { Gruta do } \\
\text { Mistério }\end{array}$ & $\begin{array}{c}S 12^{\circ} 39^{\prime} 262^{\prime \prime} \mathrm{W} \\
46^{\circ} 26^{\prime} 447^{\prime \prime}\end{array}$ & Calcário & $-60 \mathrm{~m}$ & $490 \mathrm{~m}$ \\
\hline $\begin{array}{l}\text { Gruta do Arco } \\
\text { do Mocambo }\end{array}$ & $\begin{array}{c}\text { S 12047'081" W } \\
46^{\circ} 27^{\prime} 416^{\prime \prime}\end{array}$ & Calcário & $-40 m$ & $300 \mathrm{~m}$ \\
\hline $\begin{array}{c}\text { Toca da Onça do } \\
\text { Mocambo }\end{array}$ & $\begin{array}{c}S 12^{\circ} 47^{\prime} 027^{\prime \prime} \mathrm{W} \\
46^{\circ} 26^{\prime} 44^{\prime \prime}\end{array}$ & Calcário & $-60 m$ & $400 \mathrm{~m}$ \\
\hline Gruta das Rãs & $\begin{array}{c}\text { S } 12^{\circ} 41^{\prime} 371^{\prime \prime} \mathrm{W} \\
46^{\circ} 24^{\prime} 243^{\prime \prime}\end{array}$ & Calcário & $-20 m$ & $602,30 \mathrm{~m}$ \\
\hline Gruta Sabiá & $\begin{array}{c}S 12^{\circ} 42^{\prime} 311^{\prime \prime} \mathrm{W} \\
46^{\circ} 23^{\prime} 517^{\prime \prime}\end{array}$ & Calcário & $-30 m$ & $197,10 \mathrm{~m}$ \\
\hline $\begin{array}{l}\text { Gruta da } \\
\text { Guariroba }\end{array}$ & $\begin{array}{c}\mathrm{S} 12^{\circ} 40^{\prime} 531^{\prime \prime} \mathrm{W} \\
46^{\circ} 23^{\prime} 537^{\prime \prime}\end{array}$ & Calcário & $-40 m$ & $322,70 \mathrm{~m}$ \\
\hline Gruta Cachoeira & $\begin{array}{c}S 12^{\circ} 40^{\prime} 515^{\prime \prime} \mathrm{W} \\
46^{\circ} 24^{\prime} 038^{\prime \prime}\end{array}$ & Calcário & $-45 \mathrm{~m}$ & $392,60 \mathrm{~m}$ \\
\hline
\end{tabular}

Essas dez cavernas foram exploradas, visando identificar as principais características acerca de suas dimensóes, Geoespeleologia, Bioespeleologia e ciências afins como Arqueologia e Paleontologia, além de anotaçóes das principais intervençóes antrópicas nas cavernas e seu entorno.

Em todas as cavernas foi constatada a presença de água, principalmente gotejamentos, indicando que as mesmas ainda estão em processo de evolução. As grutas da Cachoeira e 
da Guariroba apresentam água corrente (rio subterrâneo), enquanto a gruta das Rãs possui um pequeno lago em seu interior.

Os espeleotemas mais comuns encontrados nas cavernas visitadas foram estalactites, estalagmites, colunas, travertinos, microtravertinos, cortinas e escorrimentos. Entre os menos comuns, pode-se destacar a ocorrência de helictites, clavas e microtravertinos com calcita cintilante. Em algumas cavernas foi constatada a presença de scallops, indicando comportamento turbulento do fluxo subterrâneo (TRAVASSOS, 2007).

Os principais animais observados na parte interna das cavidades foram, em sua maioria, animais dos grupos: insecta, araneae, opiliones, moluscos, anfíbios e mamíferos (morcegos hematófagos, frugívoros e insetívoros). Na Gruta do Culto, observou-se répteis não encontrados em nenhuma outra cavidade da área (Amphisbeaneae alba), espécie de difícil visualização devido aos seus hábitos fossórios. Na caverna D. Conceição, foi possível observar dois tipos de fauna: araneae e ave (Tyto alba).

Sobre as ocorrências arqueológicas, pode-se destacar apenas algumas pinturas rupestres (tradições não identificadas) ocorrentes na Gruta dos Moura. Já a paleontologia da área apresenta grande potencial, com descoberta de novas espécies e possibilidades para várias pesquisas futuras (OLIVEIRA, et al., 2011). Várias escavaçóes foram realizadas, e o material coletado encontra-se em fase de identificação.

\section{6 - Consideraçóes finais}

O presente trabalho constitui uma breve abordagem sobre os aspectos gerais da área cárstica de Aurora do Tocantins. Vale ressaltar que este estudo é parte de um projeto mais abrangente, que visa a caracterização física das cavernas da porção centro-sul do estado do Tocantins.

Após os trabalhos de campo e laboratório, foi possível tecer algumas considerações acerca das feiçóes cársticas da área estudada:

Pode-se notar que a maioria das cavernas apresenta água em seu interior, principalmente gotejamentos, contribuindo para o processo de dissolução dos maciços calcários e, consequentemente, para a deposiçáo de espeleotemas.

Em algumas cavernas, como a Gruta Cachoeira e a Gruta dos Moura, pode-se observar a ocorrência de condutos com dois níveis, indicando que houve, durante o desenvolvimento da cavidade, uma mudança no nível de base local.

De maneira geral, a área possui seu uso dominado por agricultura e pastagens, merecendo destaque a porçáo leste, que apresenta grandes plantaçóes de soja. Neste tipo de monocultura extensiva costuma-se fazer uso de defensivos agrícolas, o que aumenta o potencial para a degradação dos recursos hídricos dessa área, que é de grande importância para recarga hídrica da porção leste da bacia do rio Tocantins, um dos maiores do Brasil.

Dessa forma, entende-se que este é apenas um primeiro passo de uma longa caminhada rumo ao entendimento da dinâmica da paisagem do carste da região sudeste do estado do Tocantins.

Agradecimentos - O presente estudo foi desenvolvido com auxílio do Conselho Nacional de Desenvolvimento Científico e Tecnológico - CNPq na forma de bolsa de 
produtividade em pesquisa, processo no 314759/2009-3. O autor agradece aos membros do Tocantins Espelo Grupo pela ajuda nos trabalhos de campo.

\section{Referências Bibliográficas}

BÖGLI, A. (1980) - Karst hydrology and physical speleology. Berlin/New York: Springer.

BRASIL - Ministério das Minas e Energia. Secretaria Geral (1982) - Projeto RADAMBRASIL. Folha SD 23 Brasília; geologia, geomorfologia, pedologia, vegetaçáo e uso potencial da terra. Rio de Janeiro, 660 p.

CAMPOS, J. E. G. \& DARDENE, M. A. (1997) - Estratigrafia e sedimentação da Bacia Sanfranciscana: Uma revisão. Revista Brasileira de Geociências, 27, p. 269-282.

FORD, D. C. \& WILLIAMS, P. W. (2007) - Karst geomorphology and hidrology. United Kingdom: Wiley.

KARMANN, I. \& SÁNCHEZ, L. E. (1979) - Distribuiçăo das rochas carbonáticas e Províncias espeleológicas do Brasil. Espeleo-Tema, 13, p. 105-167.

LINO, C. F. (2001) - Cavernas: O Fascinante Brasil Subterrâneo. São Paulo, Editora Gaia.

OLIVEIRA, E. V., NOVA, P. V., GOIN, F. J. \& AVILLA, L. S. (2011) - A new hyladelphine marsupial (Didelphimorphia, Didelphidae) from cave deposits of northern Brazil. Zootaxa, p. 1-12.

PALMER, A. N. (2007) - Cave geology. Cave Books, 454 p.

SEPLAN (SECRETARIA DO PLANEJAMENTO E MEIO AMBIENTE) (2008) - Atlas do Tocantins: subsídios ao planejamento da gestão territorial. Diretoria de Zoneamento Ecológico-Econômico - DZE. 4 ed. Palmas, 49 p.

SOUZA, J. D., KOSIN, M., HEINECK, C. A., LACERDA FILHO, J. V., TEIXEIRA, L. R., VALENTE, C. R., GUIMARÃES, J. T., BENTO, R. V., BORGES, V. P., SANTOS, R. A., LEITE, C. A., NEVES, J. P., OLIVEIRA, I. W. B., CARVALHO, L. M., PEREIRA, L. H. M. \& PAES, V. J. C. (2004) - Folha SD.23Brasília. In: Schobbenhaus, C.; Gonçalves, J. H.; Santos, J. O. S.; Abram, M. B.; Leão Neto, R.; Matos, G. M. M.; Vidotti, R. M.; Ramos, M. A. B. e Jesus, J. D. A. (eds.). Carta geológica do Brasil ao milionésimo, Sistemas de Informaçốes Geográficas - SIG, Programa Geologia do Brasil, CPRM, Brasília. CD-ROM.

TRAVASSOS, L. E. P. (2007) - Caracterização do carste da região de Cordisburgo, Minas Gerais. Dissertação (Mestrado) - Programa de Pós-graduação em Geografia - Tratamento da Informação Espacial. Pontifícia Universidade Católica de Minas Gerais, 98 p. 